Supporting Information

\title{
Preparation and Evaluation of Titanium-Based Xerogel as a Promising Coagulant for Water/Wastewater Treatment
}

Xiaomeng Wang, Minghui Li, Xiaojie Song, Zhihao Chen, Bingdang Wu, Shujuan Zhang*

State Key Laboratory of Pollution Control and Resource Reuse, School of the Environment, Nanjing University, 210023, PR China.

*Correspondence author. Phone: +86 258968 0389, E-mail: sjzhang@nju.edu.cn

Submitted to: Environmental Science \& Technology

This file contains 7 Text sections, 11 Figures, 2 Table, and 30 references. 


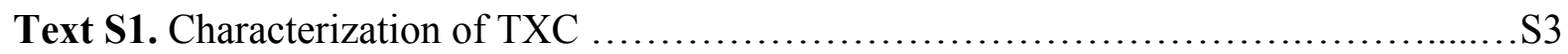

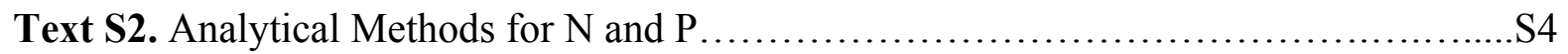

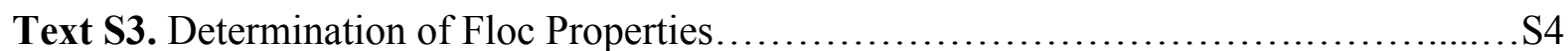

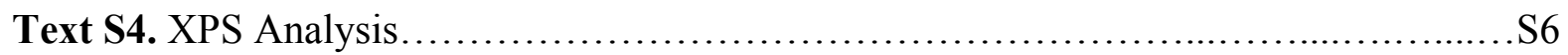

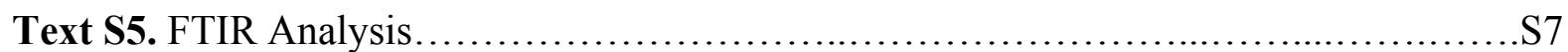

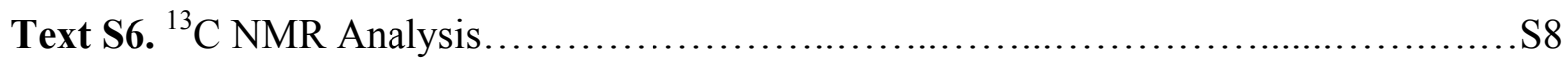

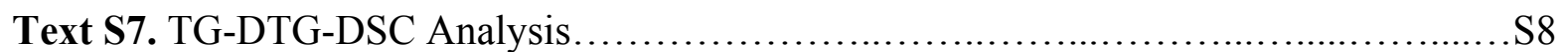

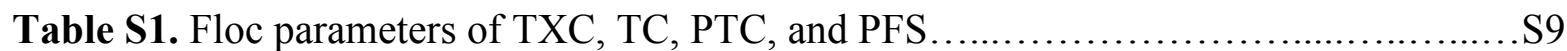

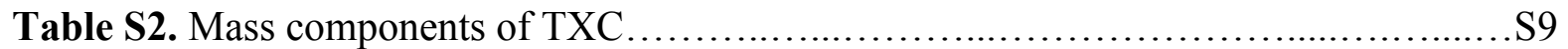

Figure S1. Effect of solution alkalinity on coagulation by TXC and TC/PTC..............S10

Figure S2. Turbidity removal from the simulated water by TXC and PFS......................S11

Figure S3. Removal of TN and TP in simulated water by TXC and TC/PTC................S11

Figure S4. Speciation-pH profile of Cr................................................... 12

Figure S5. Floc formation in the textile wastewater TW2 .................................S12

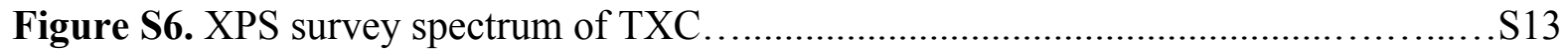

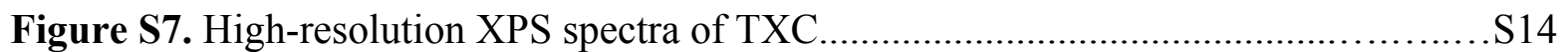

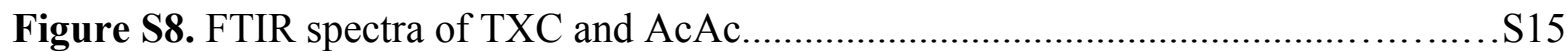

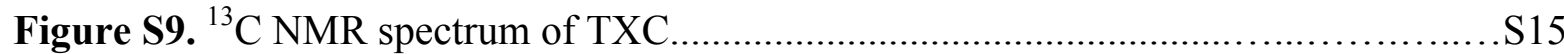

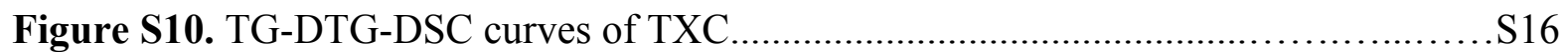

Figure S11. Schematic structure of TXC ................................................

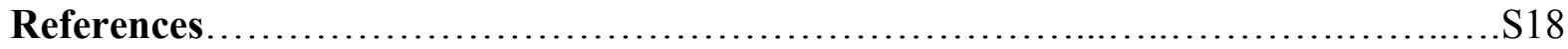




\section{Text S1. Characterization of TXC}

FTIR analysis was conducted with a Thermo NEXUS870 spectrophotometer (Nicolet Inc., USA) and the potassium bromide pallet method. XPS analysis (PHI 5000 Versa Probe spectrometer, ULVAC-PHI Co, Japan) was conducted with a monochromatic Al Ka radiation source. Thermogravimetry-differential thermogravimetry-differential scanning calorimetry (TG-DTG-DSC) was analyzed with a thermogravimetric analyzer (STA 449 C, NETZACH Co., German). ${ }^{13} \mathrm{C}$ solid-state NMR spectrum was conducted on a Bruker AVANCE III 400WB spectrometer, operating at $9.4 \mathrm{~T}$ with a frequency of $400.13 \mathrm{MHz}$. Zeta potential measurements were carried out on a Nano-Zetasizer (Malvern Co., UK). Morphology of TXC and TC hydrolysates was observed by TEM (JEM-200CX, JEM Co., Japan) under an accelerating voltage of $120 \mathrm{kV}$. The $\mathrm{Ti}$ and $\mathrm{Cl}$ contents in dissolved TXC solutions were determined with an atom absorb graphite ingle (AAS-M6, Thermo Co., USA) and an ion chromatography (IC-1100, Dionex Co., USA), respectively. The content of AcAc in dissolved TXC was measured with a high performance liquid chromatography (Breeze ${ }^{\mathrm{TM}}$, Waters Co., USA). ${ }^{1}$ The alkalinity of the coagulants was determined with the acid-base titration method. In the titration, sodium fluoride was used as a masking agent to inhibit the combination between $\mathrm{Ti}$ and $\mathrm{OH}$. 


\section{Text S2. Analytical Methods for $\mathbf{N}$ and $\mathbf{P}$}

$\mathrm{N}$ and $\mathrm{P}$ were measured according to the national standard methods of China. The experimental details were as follows:

1) Total nitrogen $(\mathrm{TN})$ was determined with the alkaline potassium persulfate digestion UV spectrophotometric method (GB 11894-89). ${ }^{2}$ Ammonia nitrogen $\left(\mathrm{NH}_{4}-\mathrm{N}\right)$ was determined with the Nessler's reagent colormetric method (GB 7479-1987). ${ }^{3}$ Nitrate nitrogen $\left(\mathrm{NO}_{3}-\mathrm{N}\right)$ was measured by the UV spectrophotometric method (GB 7493-87). ${ }^{4}$ The content of organic nitrogen $\left(\right.$ Org-N) was calculated by subtracting the sum of $\mathrm{NO}_{3}-\mathrm{N}$ and $\mathrm{NH}_{4}-\mathrm{N}$ from $\mathrm{TN}$.

2) Total phosphorus (TP) was determined with the potassium persulfate digestion ammonium molybdate spectrophotometric method (GB 11893-89). ${ }^{5}$ Orthophosphate $\left(\mathrm{PO}_{4}-\mathrm{P}\right)$ was detected with the ammonium molybdate spectrophotometric method. The content of organic phosphorus (Org-P) was the difference between TP and $\mathrm{PO}_{4}-\mathrm{P}$.

\section{Text S3. Determination of Floc Properties}

Floc formation, breakage and regrowth tests were conducted following the two steps as mentioned in the main text. After the slow stirring period, the suspension was exposed to a high shear force $(200 \mathrm{rpm})$ for $3 \mathrm{~min}$, and another $15 \mathrm{~min}$ of slow stirring at $40 \mathrm{rpm}$ for floc regrowth. Volume-weighted mean diameter $\left(d_{\mathrm{V}}, \mu \mathrm{m}\right)$ was applied to express the floc size, which was calculated by the data processing software according to Mie's scattering theory.

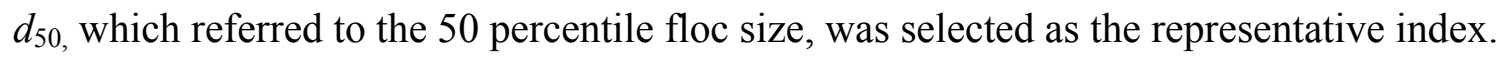

Floc fractal dimension $\left(D_{\mathrm{f}}\right)$ is an index representing the compactness degree of the primary particles. A high $D_{\mathrm{f}}$ means that the primary particles in an aggregate are arranged compactly, while a low $D_{\mathrm{f}}$ comes from highly branched and loosely bound structure. It could 
be determined by the light scattering method from the negative slope of log-log plot by a well-known power-law relation:,6,7

$$
I \propto Q^{D_{f}}
$$

where $I$ is the light intensity, and $Q$ is the scatter vector which can be given according to the following equation:

$$
Q=\frac{4 \pi n \sin (\theta / 2)}{\lambda}
$$

where $\lambda$ is the wavelength of radiation in vacuum (633 $\mathrm{nm}$ in this work), $n$ is the refractive index of the dispersion medium (1.33 for water), and $\theta$ is the scattering angle, respectively.

Floc growth rate $(\Delta G)$ is expressed as the slope of the floc growth phase:

$$
\Delta G=\frac{\Delta s i z e}{\Delta t}
$$

Floc strength factor $\left(S_{\mathrm{f}}\right)$ and recovery factor $\left(R_{\mathrm{f}}\right)$ are used to assess floc strength and recoverability. ${ }^{6,8} S_{\mathrm{f}}$ refers to the ability to resist rupture by a velocity gradient, while $R_{\mathrm{f}}$ indicates floc recovery ability. They can be calculated as follows:

$$
\begin{aligned}
& S_{\mathrm{f}}=\frac{d_{2}}{d_{1}} 100 \\
& D_{\mathrm{f}}=\frac{d_{3}-d_{2}}{d_{1}-d_{2}} 100
\end{aligned}
$$

where $d_{1}, d_{2}$, and $d_{3}$ are the average floc size of the plateau in the floc size profile before breakage, after breakage and the new plateau after regrowth, respectively. 


\section{Text S4. XPS Analysis}

The results in Figure S6 indicate that the photoelectron peak for Ti $2 p$ appeared clearly at a binding energy of $458 \mathrm{eV}$ and $\mathrm{O} 1 \mathrm{~s}$ at $531 \mathrm{eV}$. The $\mathrm{C} 1 \mathrm{~s}$ and $\mathrm{Cl} 2 \mathrm{p}$ photoelectron peaks were at binding energies of $284 \mathrm{eV}$ and $197 \mathrm{eV}$, respectively. No any other element was introduced during the preparation process.

As shown in the high-resolution spectra, the $\mathrm{O}$ 1s peak (Figure S7a) could be deconvolved into four distinguishable peaks centered at binding energies of 530.0, 531.5, 532.5 and $533.3 \mathrm{eV}$, respectively. The band at $530.0 \mathrm{eV}$ came from the lattice oxygen in the Ti-O bond. ${ }^{9}$ The other three peaks could be assigned to hydroxyl group, ${ }^{10} \mathrm{C}-\mathrm{O}$ bond ${ }^{11}$ and adsorbed $\mathrm{H}_{2} \mathrm{O},{ }^{11}$ respectively. The $\mathrm{C} 1 \mathrm{~s}$ spectrum was composed of three peaks at 284.7 , 286.4 and $288.6 \mathrm{eV}$ (Figure S7b), assigning to the adventitious carbon from the ambient and the $\mathrm{C}-\mathrm{C}$ bond of $\mathrm{AcAc},{ }^{10} \mathrm{C}-\mathrm{O}$ bond, ${ }^{12-14}$ and $\mathrm{C}=\mathrm{O}$ bond, ${ }^{15,16}$ respectively. In the XPS spectrum of $\mathrm{Cl} 2 \mathrm{p}$ (Figure S7c), the two peaks at $198.8 \mathrm{eV}\left(\mathrm{Cl} 2 \mathrm{p}_{3 / 2}\right)$ and $199.5\left(\mathrm{Cl} 2 \mathrm{p}_{1 / 2}\right)$ could be attributed to Ti-Cl bond, ${ }^{17,18}$ while the peak at $197.8 \mathrm{eV}$ might come from $\mathrm{Cl}-\mathrm{OH}$ bond. 


\section{Text S5. FTIR Analysis}

The chemical structure of TXC and free AcAc were analyzed by FTIR (Figure S8). From a qualitative point of view, the spectrum of TXC was similar to that of the reddish-brown particles $\mathrm{TiO}(\mathrm{AcAc})_{2}{ }^{19} \mathrm{TXC}$ had a wide band at $3286 \mathrm{~cm}^{-1}$ originating from the stretching vibration of Ti-OH bond. ${ }^{20,21}$ Specifically, TXC contained three characteristic vibrations at 1618,1564 and $1532 \mathrm{~cm}^{-1}$, shifting to lower frequency regions as compared to AcAc. The three vibrations could be associated with the stretching vibrations of the $\mathrm{C}=\mathrm{O}$ bond of keto and enol, and the $\mathrm{C}=\mathrm{C}$ bond of enol bounded to $\mathrm{Ti}^{4+}$ ions, ${ }^{22}$ respectively. The enol-keto tautomers of AcAc displayed a doublet at 1727 and $1707 \mathrm{~cm}^{-1}$, corresponding to the $\mathrm{C}=\mathrm{O}$ stretching vibration of keto and enol, respectively. Furthermore, the $\mathrm{C}=\mathrm{C}$ stretching vibration of enol was manifested as a strong band at $1605 \mathrm{~cm}^{-1} \cdot{ }^{19}$ It is well known that AcAc could chelate with transition metals through the enolic $\mathrm{OH}$ to form chelated complexes. ${ }^{23}$ As a result, the carbonyl stretching band of AcAc group after binding with metal ion would be affected, which had been observed in its complexes with transition metals, including $\mathrm{Fe}^{24}$ $\mathrm{Cr},{ }^{25} \mathrm{Ni},{ }^{26} \mathrm{Gd}$ and Ce. ${ }^{19}$ In all cases, the characteristic vibrations of AcAc group shifted to low frequency regions. Therefore, the shift of the $\mathrm{C}=\mathrm{O}$ peaks to lower frequency region in the FTIR spectrum of TXC demonstrated the chelation of AcAc with $\mathrm{Ti}^{4+}$. 


\section{Text S6. ${ }^{13}$ C NMR Analysis}

The data for the ${ }^{13} \mathrm{C}$ NMR chemical shifts of the material are given in Figure S9. The ${ }^{13} \mathrm{C}$ NMR spectrum revealed many features characteristic of AcAc. AcAc groups gave rise to three peaks at 27.0, 107.6 and $193.4 \mathrm{ppm}$ corresponding to the methyl, methane, and carbonyl groups of AcAc, respectively. ${ }^{22,27}$ The other two peaks at 18.2 and 62.3 ppm are attributed to the methyl and methylol of ethanol. ${ }^{28}$

\section{Text S7. TG-DTG-DSC Analysis}

Figure S10 shows the thermal behavior of TXC by depicting the TG, DTG and DSC curves. Three mass loss steps could be detected according to the DTG curve. The first mass loss step between $30-166^{\circ} \mathrm{C}$ was an endothermic reaction with a mass loss of $23.0 \%$, corresponding to the evolution of adsorbed or weakly bounded water and solvent. The following DTG maxima at 206 and $408^{\circ} \mathrm{C}$ were exothermic reactions with the observed mass loss 13.6 and $9.3 \%$, respectively. AcAc in TXC would be decomposed in the temperature interval of $303-500^{\circ} \mathrm{C}^{29,30}$ Residual $\mathrm{Cl}$ would be released when the temperature ranged from 166 to $303^{\circ} \mathrm{C}$. 
Table S1. Floc parameters of TXC, TC, PTC, and PFS. ${ }^{\text {a }}$

\begin{tabular}{lcccccc}
\hline Coagulant & $\boldsymbol{d}_{\mathbf{1}}$ & $\boldsymbol{d}_{\mathbf{2}}$ & $\boldsymbol{d}_{\mathbf{3}}$ & $\boldsymbol{\Delta G}$ & $\boldsymbol{S}_{\mathbf{f}}$ & $\boldsymbol{R}_{\mathbf{f}}$ \\
\hline TXC & 1234 & 364 & 414 & 947.7 & 29.5 & 5.7 \\
TC & 997 & 221 & 340 & 291.9 & 22.2 & 15.3 \\
PTC & 1019 & 224 & 361 & 392.6 & 21.9 & 17.2 \\
PFS & 449 & 160 & 247 & 96.7 & 36.1 & 29.9 \\
\hline
\end{tabular}

${ }^{a}$ Experimental conditions are the same at those in Figure 6.

Table S2. Element composition in TXC

\begin{tabular}{lccccc}
\hline & $\mathrm{Ti}$ & $\mathrm{Cl}$ & $\mathrm{AcAc}$ & $\mathrm{OH}$ & $\mathrm{O}^{\mathrm{a}}$ \\
\hline Mass faction $(\mathrm{mg} / \mathrm{g})$ & 0.203 & 0.147 & 0.108 & 0.036 & 0.282 \\
Mole mass $(\mathrm{mmol} / \mathrm{g})$ & 4.24 & 4.14 & 1.08 & 2.10 & 17.6 \\
Mole ratio to $\mathrm{Ti}$ & 1 & 1 & 0.25 & 0.5 & 4.1 \\
\hline
\end{tabular}

${ }^{\text {a }}$ Calculated as the difference between the residual mass in the TG curve at $700^{\circ} \mathrm{C}$ and the mass of $\mathrm{Ti}$ and $\mathrm{OH}$ 


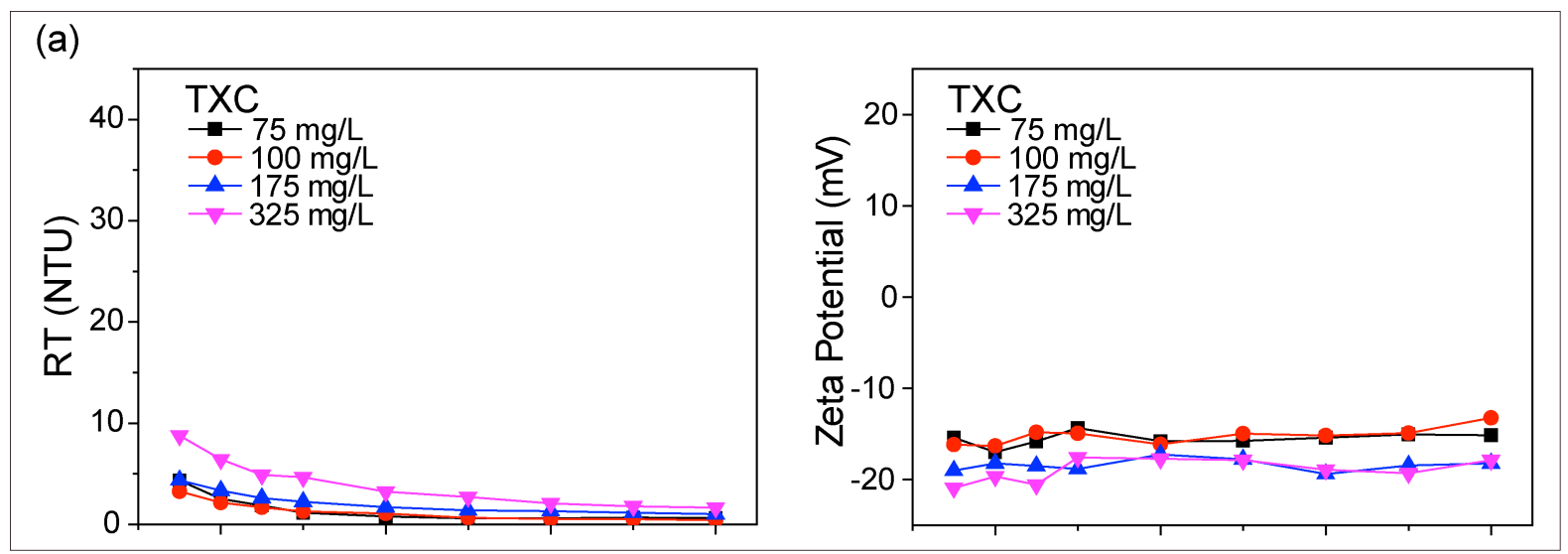

(b)
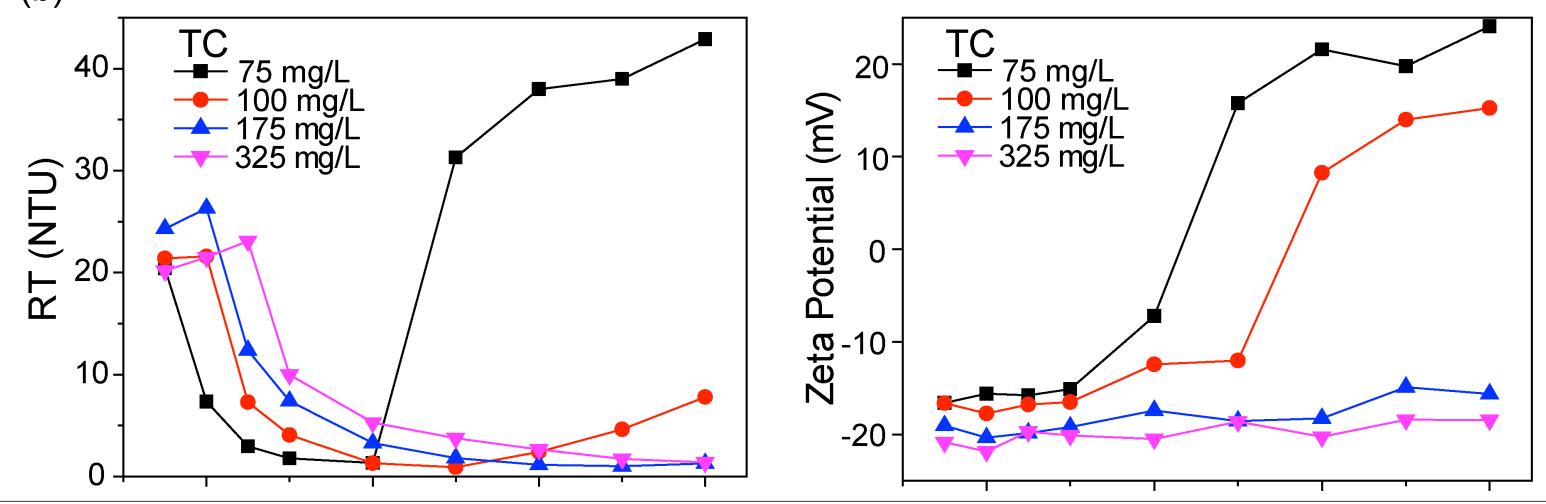

(c)
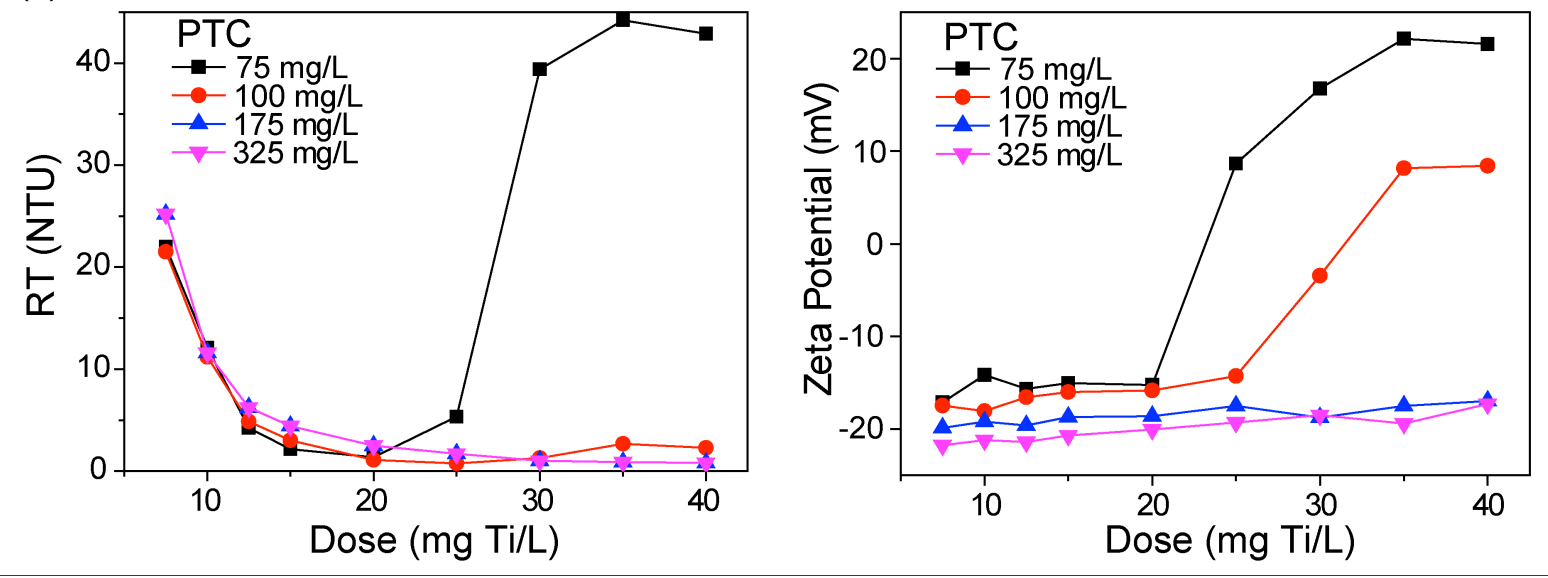

Figure S1. Effects of alkalinity on turbidity removal and zeta potential. (a) TXC, (b) TC, (c)

PTC. The alkalinity was adjusted with $\mathrm{NaHCO}_{3}$ and was expressed in $\mathrm{mg} / \mathrm{L}$ as $\mathrm{CaCO}_{3}$. 
(a)

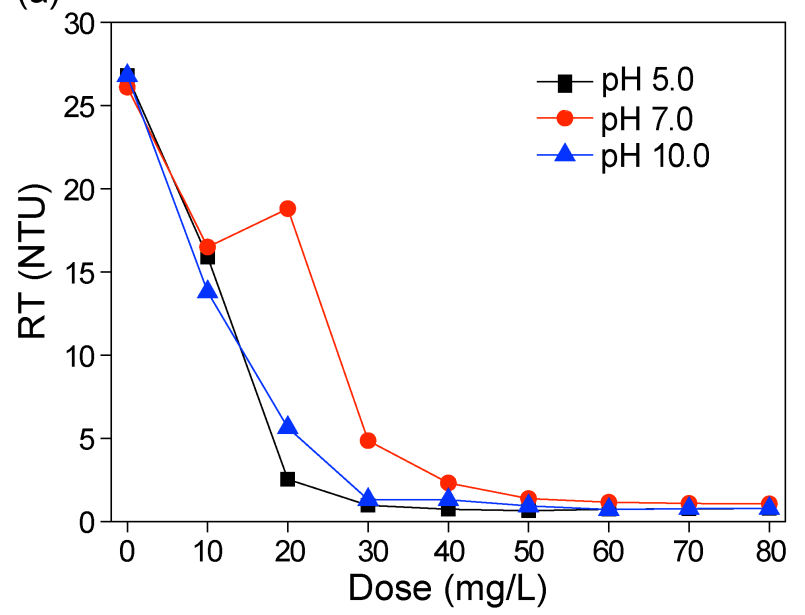

(b)

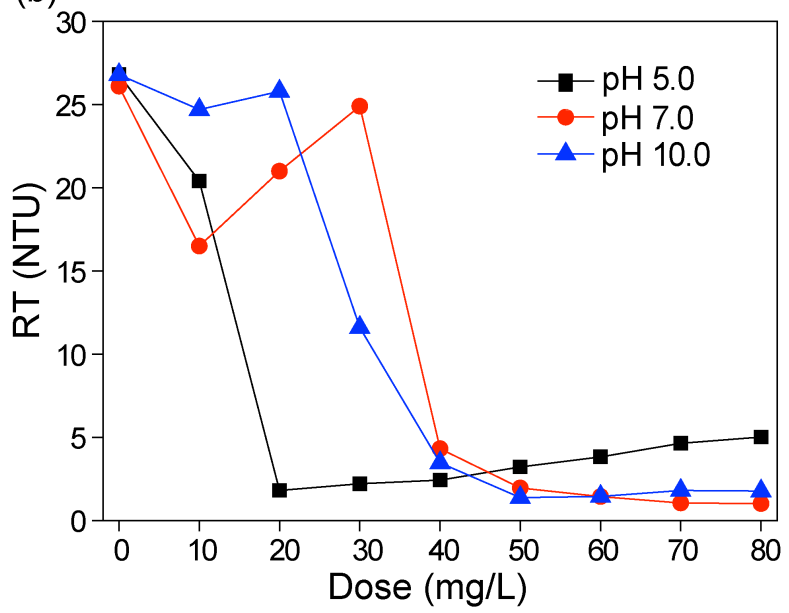

Figure S2. Residual turbidity of the simulated water as a function of coagulant dose. (a) TXC, (b) PFS.

(a)

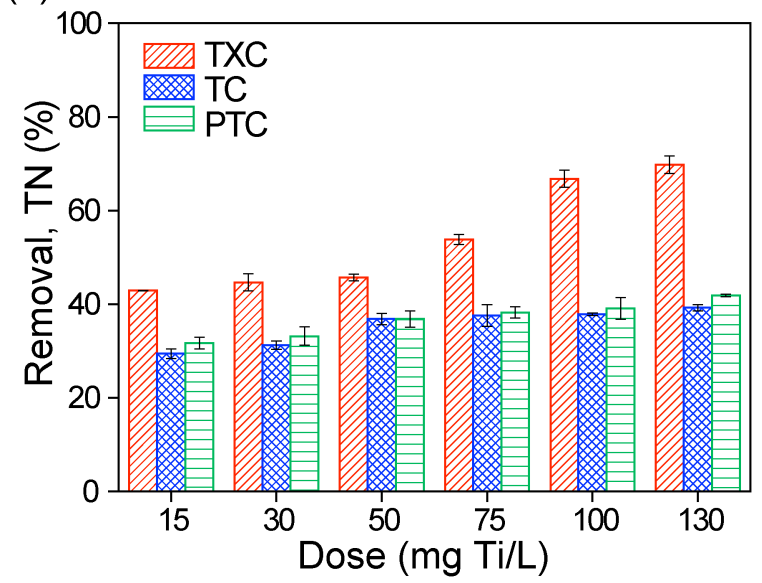

(b)

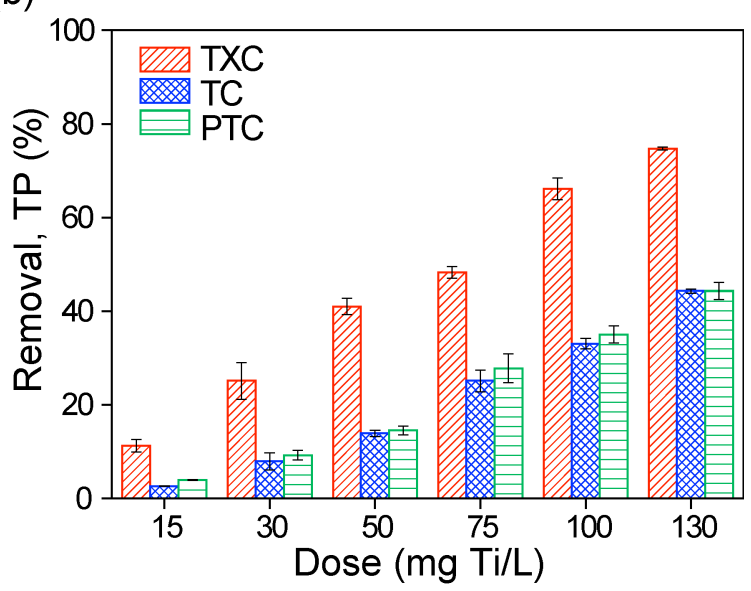

Figure S3. TN (a) and TP (b) removal from the N/P simulated water by TXC, TC and PTC as a function of coagulant dose. Initial $\mathrm{pH}: 7.0, \mathrm{TN}: 38.8 \mathrm{mg} / \mathrm{L}, \mathrm{TP}: 30.0 \mathrm{mg} / \mathrm{L}$. 


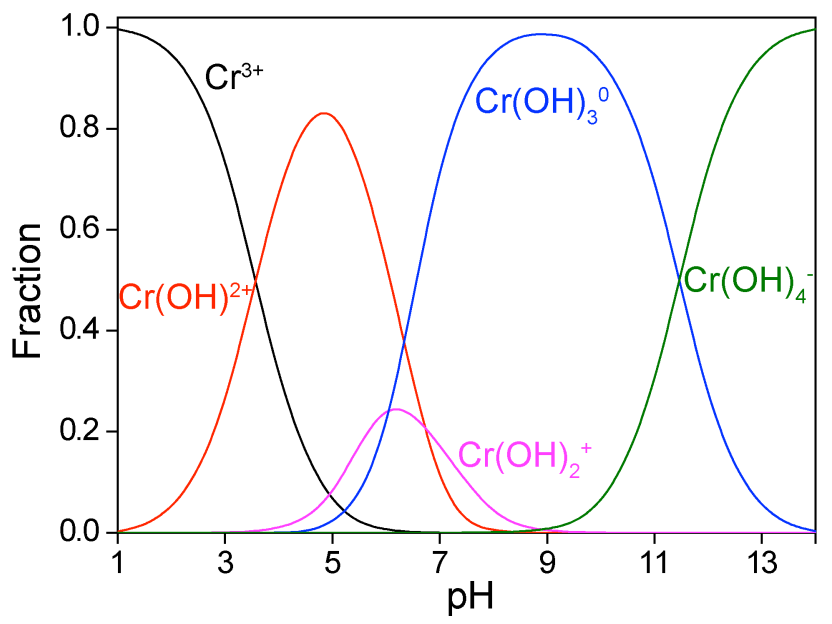

Figure S4. The speciation-pH profile of Cr.
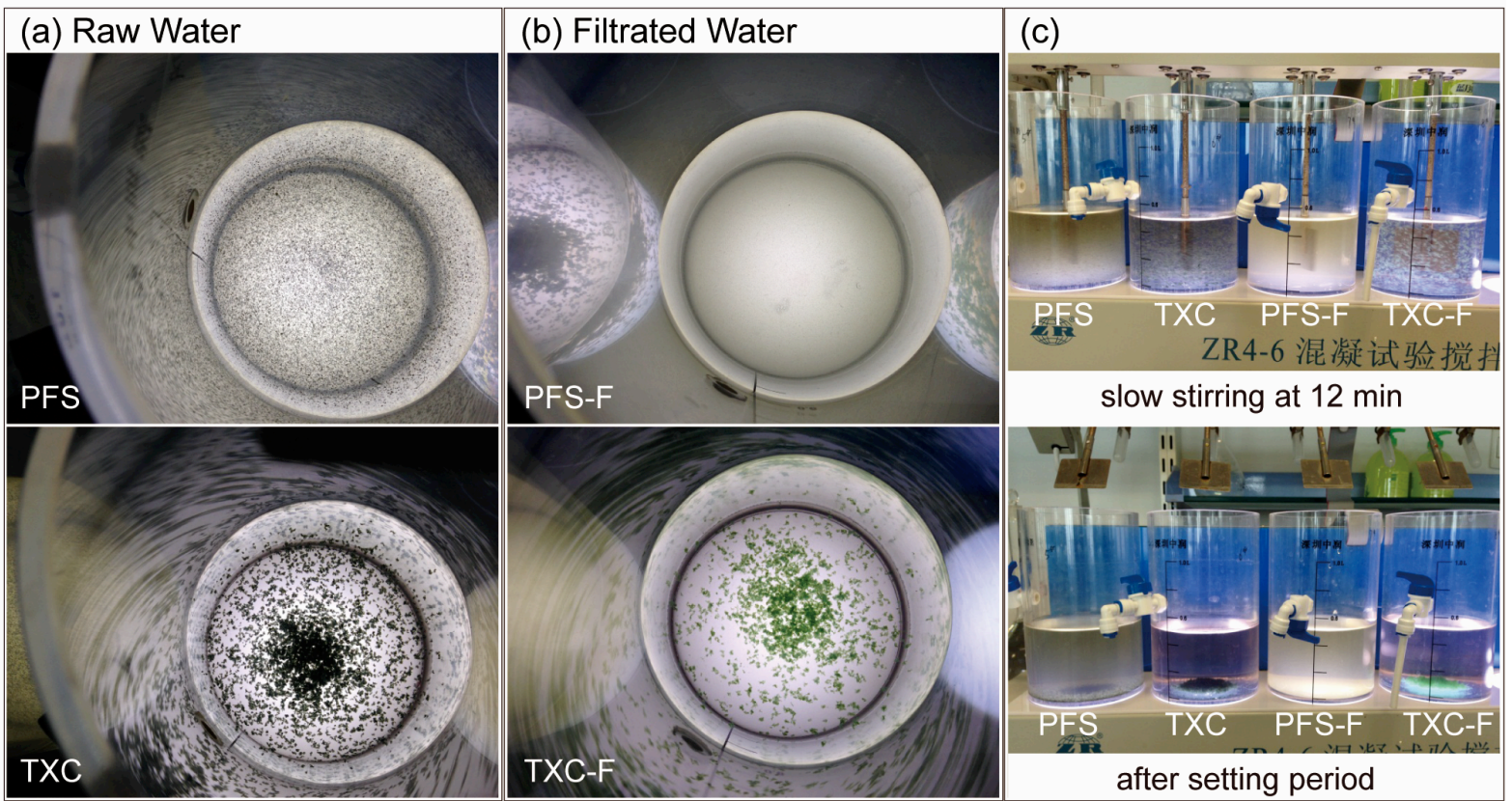

Figure S5. Floc formation and settling in the raw and filtrated (-F) textile wastewater TW2.

(a) and (b): top view pictures during stirring, (c): side view pictures at the slow stirring period and after setting. Initial turbidity: $17 \mathrm{NTU}, \mathrm{pH}: 8.3$, dose: $40 \mathrm{mg} / \mathrm{L}$. 


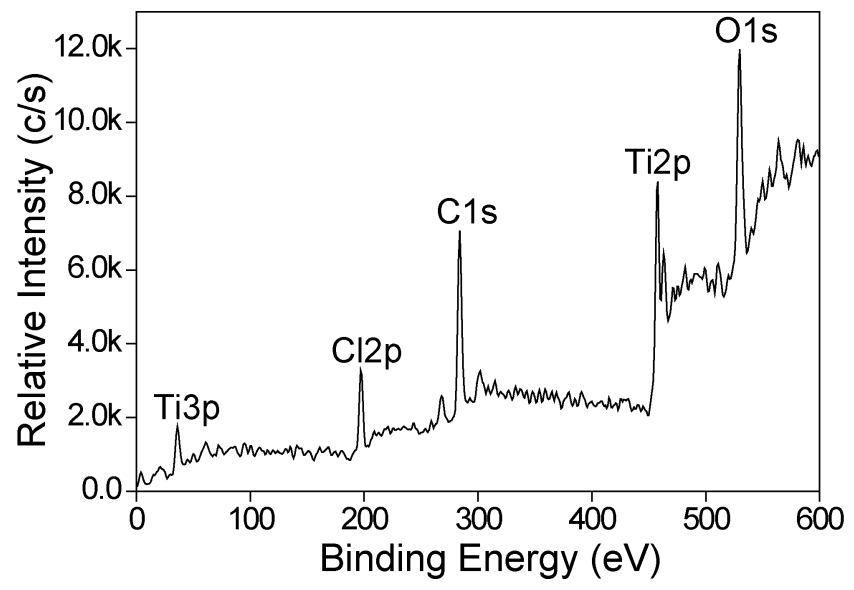

Figure S6. XPS survey spectrum of TXC. 

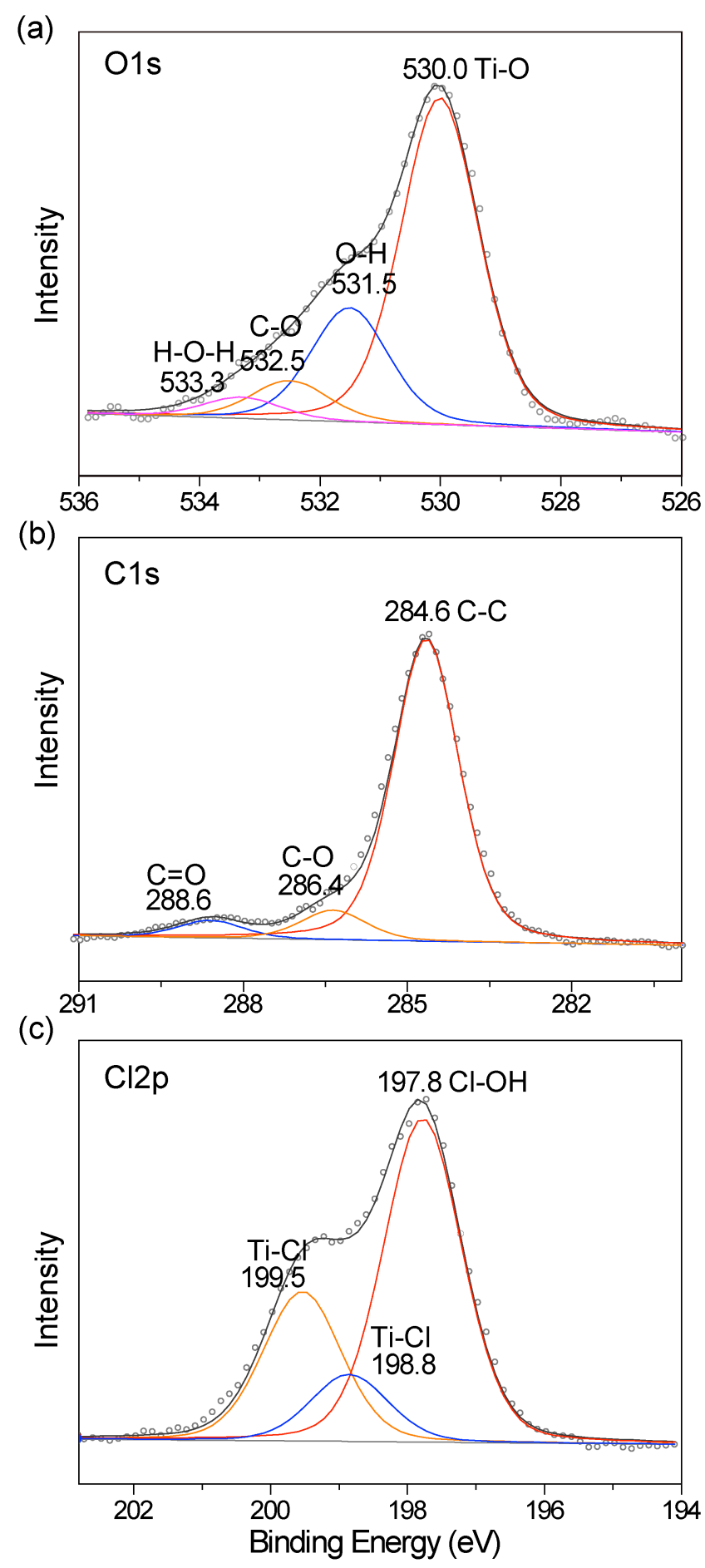

Figure S7. High-resolution XPS spectra of TXC. The empty circles are data points and the solid black lines are the simulated ones. 


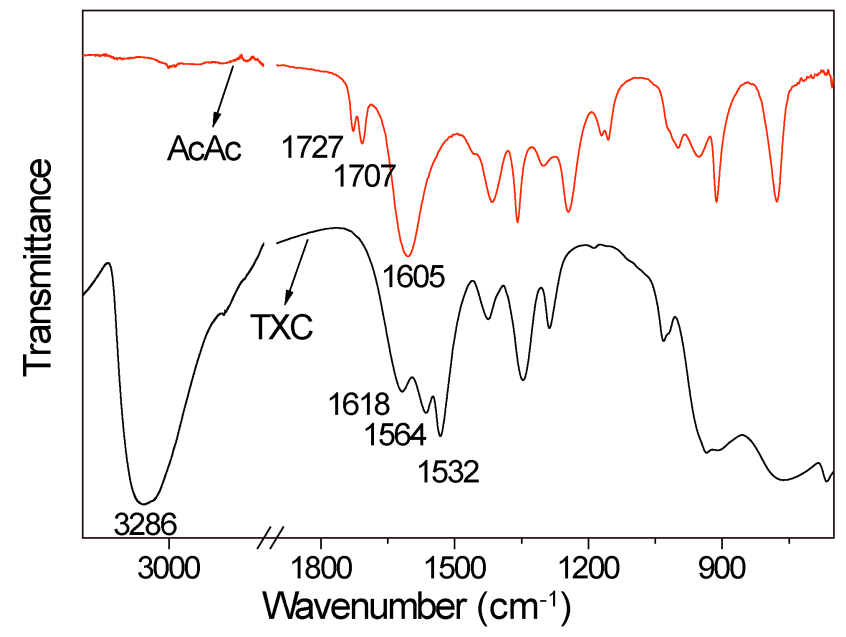

Figure S8. FTIR spectra of TXC and free AcAc.

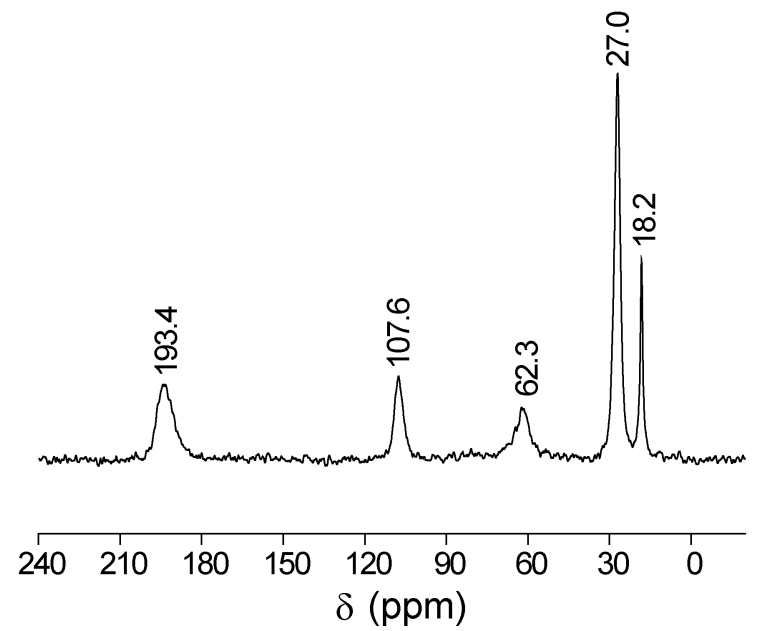

Figure S9. ${ }^{13} \mathrm{C}$ NMR spectrum of TXC. 


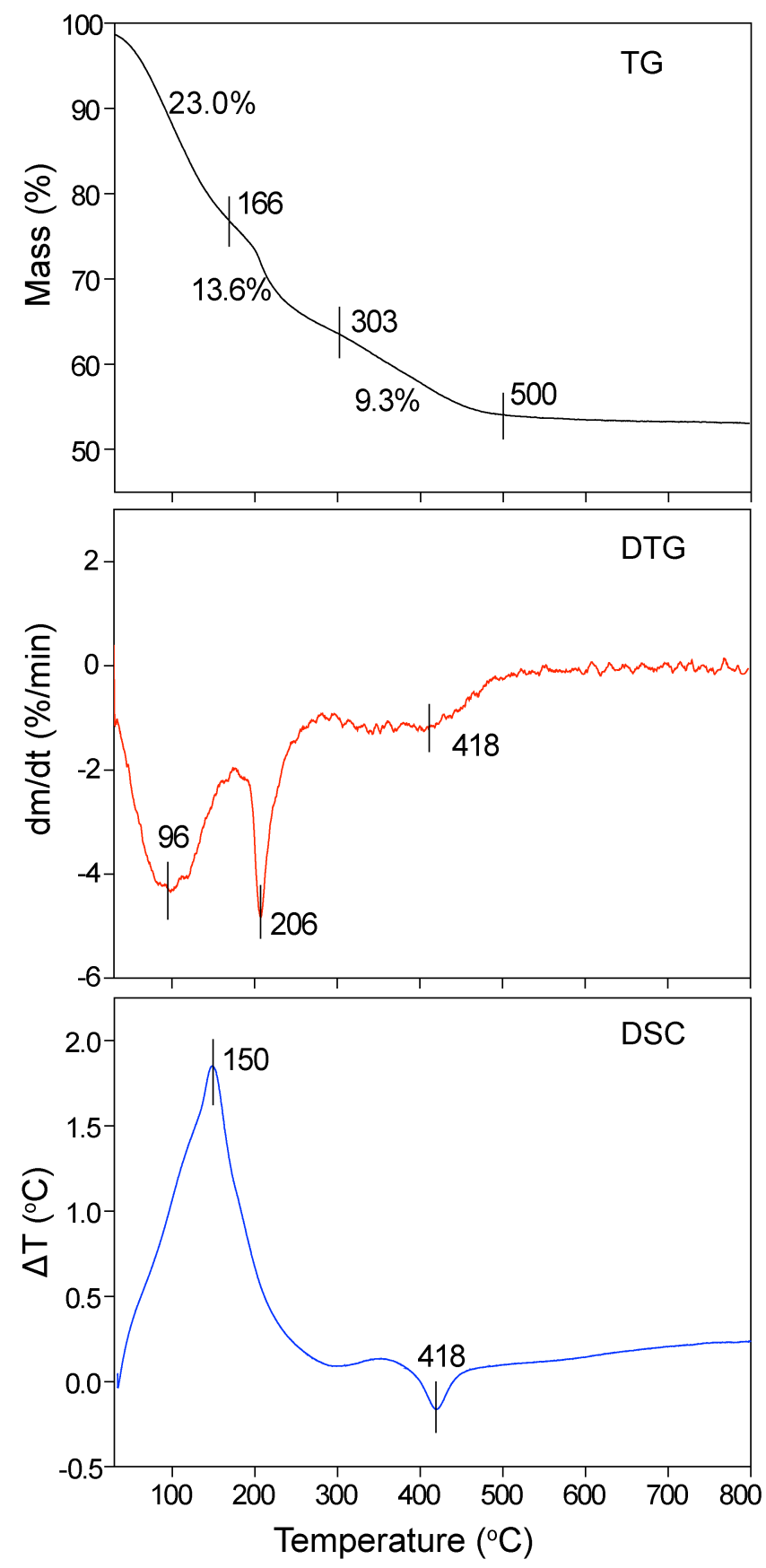

Figure S10. TG, DTG and DSC curves of TXC at $20^{\circ} \mathrm{C} \mathrm{min}^{-1}$ in a $\mathrm{N}_{2}$ flow. 


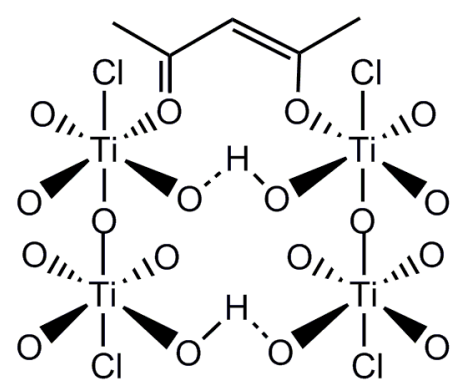

Figure S11. The schematic structure of TXC. 


\section{REFERENCES}

(1) Wu, B. D.; Zhang, S. J.; Li, X. C.; Liu, X. T.; Pan, B. C. Iron in non-hydroxyl radical mediated photochemical processes for dye degradation: Catalyst or inhibitor? Chemosphere 2015, 131, 55-62.

(2) GB 11894-89. Water quality-Determination of total nitrogen-Alkaline potassium persulfate digestion-UV spectrophometric method. State Environmental Protection of China, 1990-07-01.

(3) GB 7479-87. Water quality-Determination of ammonium-Nessler's reagent colorimetric method. State Environmental Protection of China, 1987-08-01.

(4) GB 7493-87. Water quality-Determination of nitrogen (nitrite)-Spectrophotometric method. State Environmental Protection of China, 1987-08-01.

(5) GB 11893-89. Water quality-Determination of total phosphorus-Ammonium molybdate spectrophotometric method. State Environmental Protection of China, 1990-07-01.

(6) Jarvis, P.; Jefferson, B.; Parsons, S. A. Breakage, regrowth, and fractal nature of natural organic matter flocs. Environ. Sci. Technol. 2005, 39 (7), 2307-2314.

(7) Greenwood, J.; Rainey, T.; Doherty, W. O. Light scattering study on the size and structure of calcium phosphate/hydroxyapatite flocs formed in sugar solutions. $J$. Colloid. Interf. Science 2007, 306 (1), 66-71.

(8) Francois, R. Strength of aluminium hydroxide flocs. Water Res. 1987, 21 (9), 1023-1030.

(9) Ketteler, G.; Yamamoto, S.; Bluhm, H.; Andersson, K.; Starr, D. E.; Ogletree, D. F.; Ogasawara, H.; Nilsson, A.; Salmeron, M. The nature of water nucleation sites on $\mathrm{TiO}_{2}$ (110) surfaces revealed by ambient pressure X-ray photoelectron spectroscopy. J. Phys. Chem. C 2007, 111 (23), 8278-8282.

(10) Yu, J. G.; Zhao, X. J.; Du, J. C.; Chen, W. M. Preparation, microstructure and photocatalytic activity of the porous $\mathrm{TiO}_{2}$ anatase coating by sol-gel processing. $J$. Sol-gel Sci. Technol. 2000, 17 (2), 163-171. 
(11) Reddy, B. M.; Ganesh, I.; Reddy, E. P. Study of dispersion and thermal stability of $\mathrm{V}_{2} \mathrm{O}_{5} / \mathrm{TiO}_{2}-\mathrm{SiO}_{2}$ catalysts by XPS and other techniques. J. Phys. Chem. B 1997, 101 (10), 1769-1774.

(12) Wang, X. M.; Yang, S. G.; Li, H.; Zhao, W.; Sun, C.; He, H. High adsorption and efficient visible-light-photodegradation for cationic Rhodamine B with microspheric BiOI photocatalyst. RSC Adv. 2014, 4 (80), 42530-42537.

(13) Chen, C.; Cai, W. M.; Long, M. C.; Zhou, B. X.; Wu, Y. H.; Wu, D. Y.; Feng, Y. J. Synthesis of visible-light responsive graphene oxide/ $\mathrm{TiO}_{2}$ composites with $\mathrm{p} / \mathrm{n}$ heterojunction. ACS Nano 2010, 4 (11), 6425-6432.

(14) Zhang, W. X.; Cui, J. C.; Tao, C. A.; Wu, Y. G.; Li, Z. P.; Ma, L.; Wen, Y. Q.; Li, G. T. A strategy for producing pure single-layer graphene sheets based on a confined self-assembly approach. Angew. Chem. 2009, 121 (32), 5978-5982.

(15) Fu, R.; Yoshizawa, N.; Dresselhaus, M. S.; Dresselhaus, G.; Satcher, J. H.; Baumann, T. F. XPS study of copper-doped carbon aerogels. Langmuir 2002, 18 (26), 10100-10104.

(16) Wild, U.; Pfander, N.; Schlogl, R. Species analysis of automotive carbon particles: Application of XPS for integral analysis of filter samples. Fresen. J. Anal. Chem. 1997, 357 (4), 420-428.

(17) Léon, A.; Kircher, O.; Fichtner, M.; Rothe, J.; Schild, D. Evolution of the local structure around Ti Atoms in $\mathrm{NaAlH}_{4}$ doped with $\mathrm{TiCl}_{3}$ or $\mathrm{Ti}_{13} \cdot 6 \mathrm{THF}$ by ball milling using X-ray absorption and X-ray photoelectron spectroscopy. J. Phys. Chem. B 2006, 110 (3), 1192-1200.

(18) Testova, N. V.; Shalygin, A. S.; Kaichev, V. V.; Glazneva, T. S.; Paukshtis, E. A.; Parmon, V. N. Oxidative dehydrogenation of propane by molecular chlorine. Appl. Catal. A-Gen. 2015, 505, 441-446.

(19) Shen, C. H.; Shaw, L. L. FTIR analysis of the hydrolysis rate in the sol-gel formation of gadolinia-doped ceria with acetylacetonate precursors. J. Sol-gel Sci. Technol. 2010, 53 (3), 571-577. 
(20) Krunks, M.; Oja, I.; Tonsuaadu, K.; Es-Souni, M.; Gruselle, M.; Niinisto, L. Thermoanalytical study of acetylacetonate-modified titanium (IV) isopropoxide as a precursor for $\mathrm{TiO}_{2}$ films. J. Therm. Anal. Calorim. 2005, 80 (2), 483-488.

(21) Sanchez, E.; Lopez, T.; Gomez, R.; Morales, A.; Novaro, O. Synthesis and characterization of sol-gel Pt/TiO 2 catalyst. J. Solid State Chem. 1996, 122 (2), 309-314.

(22) Leaustic, A.; Babonneau, F.; Livage, J. Structural investigation of the hydrolysis-condensation process of titanium alkoxides $\mathrm{Ti}(\mathrm{OR})_{4}(\mathrm{OR}=\mathrm{OPr}$-iso, $\mathrm{OEt})$ modified by acetylacetone. 1. Study of the alkoxide modification. Chem. Mater. 1989, 1 (2), 240-247.

(23) Mehrotra, R.C. Chemistry of metal $\beta$-diketonates. Pure Appl. Chem. 1988, 60, $1349-1356$.

(24) Brasil, M. C.; Benvenutti, E. V.; Gregório, J. R.; Gerbase, A. E. Iron acetylacetonate complex anchored on silica xerogel polymer. React. Funct. Polym. 2005, 63 (2), $135-141$.

(25) Plyuto, Y. V.; Babich, I. V.; Sheldon, R. A. AlPO $4-5$ molecular sieve modified with $\mathrm{Cr}$ (acac) $)_{3}$. App. Surf. Sci. 1999, 140 (1), 176-181.

(26) Babich, I.; Plyuto, Y. V.; Van Langeveld, A.; Moulijn, J. Role of the support nature in chemisorption of $\mathrm{Ni}(\mathrm{acac})_{2}$ on the surface of silica and alumina. App. Surf. Sci. 1997, $115(3), 267-272$.

(27) Wilkie, C. A.; Harworth, D. T. A. ${ }^{13}$ C NMR study of some metal acetylacetone complexes. J. Inorg. Nucl. Chem. 1978, 40 (2), 195-197.

(28) Mizuno, K.; Miyashita, Y.; Shindo, Y.; Ogawa, H. NMR and FT-IR studies of hydrogen bonds in ethanol-water mixtures. J. Phys. Chem. 1995, 99 (10), 3225-3228.

(29) Acik, I. O.; Madarasz, J.; Krunks, M.; Tonsuaadu, K.; Janke, D.; Pokol, G.; Niinisto, L. Thermoanalytical studies of titanium (IV) acetylacetonate xerogels with emphasis on evolved gas analysis. J. Therm. Anal. Calorm. 2007, 88 (2), 557-563.

(30) Hoene, J. V.; Charles, R. G.; Hickam, W. M. Thermal decomposition of metal 
acetylacetonates: mass spectrometer studies. J. Phys. Chem. 1958, 62 (9), 1098-1101. 